\title{
Juárez y Maximiliano: cruces entre la literatura y el cine, 1924-1933
}

\section{Juarez and Maximilian: interrelations between literature and cinematography, 1924-1933}

María del Sol Morales Zea ${ }^{1}$

maria.zea.85@gmail.com

Resumen: A través del análisis comparado y la teoría de la recepción se analizan dos obras, Juarez und Maximilian, drama escrito en Viena por Franz Werfel, y "Juárez y Maximiliano", película dirigida por Miguel contreras Torres en México. Aunque se trata de obras que reflejan el contexto en el que se desarrollaron, sus autores tienen similitudes profundas; por lo que su análisis nos permite adentrarnos a las líneas de pensamiento presentes en la primera mitad del siglo xx. Al estudiar la recepción de estas obras podemos entrever los fines que sus autores prefiguraron en el momento de su elaboración, así como la aceptación o rechazo que recibieron. Finalmente, el análisis permite reconocer las ideas políticas y las interpretaciones de la historia que circulaban en los ańos de sus respectivos estrenos.

Palabras clave: Juárez, Maximiliano, literatura, cine, recepción.

${ }^{1}$ Este artículo se realizó con el apoyo de la beca de estancia posdoctoral nacional Conacyt 2019-2020, dentro del programa de Maestría en Literatura Hispanoamericana de la Universidad de Guanajuato. 
Abstract: This text is an approach to two works from comparative analysis and reception theory: Juarez und Maximilian, drama written in Vienna by Franz Werfel, and "Juárez y Maximiliano", movie directed by Miguel Contreras Torres in Mexico. Although this works reflects the context in which authors developed, they have deep similarities; therefore, its analysis allows us to get into the lines of thought of the first half twenty century. Study the reception of this works offers a vision of the ends that its authors prefigured at time of its elaborations, as well as acceptance or rejection. Finally, this paper exposes political ideas and history interpretations that existed in the years of its premieres.

Keywords: Juarez, Maximilian, Literature, Cinematography, Reception.

Recibido: 4 de diciembre de 2019 Aceptado: Io de abril de 2020 https://dx.doi.org/IO.I 5 I74/rv.vi3i27.5 I

$\square \mathrm{n}$ el presente trabajo se analizará el binomio "Juárez y MaxiEmiliano" (obra teatral-película) a lo largo de su desarrollo que atraviesa dos lenguajes: el literario (en su vertiente específica del drama) y el cinematográfico, los cuales presentan afinidades, pero también particularidades propias de su medio. El punto de convergencia teórica lo constituirá la "prefiguración” del público en ambas representaciones. La interacción entre actores y público, tanto en el espacio de la representación dramática como en el de la representación cinematográfica, resultan vitales para la articulación de dichas propuestas artísticas en términos lingüísticos, escenográficos, de temporalidad (duración), entre otras. En ese sentido, resaltan las diferencias y similitudes de las sociedades que las reciben; por un lado, la Austria desmembrada, en la que conviven nostálgicos del imperio con proyectistas del nuevo Estado; por el otro, el México posrevolucionario, que busca la consolidación de 
un discurso nacionalista que concilie la historia del siglo XIX con la del siglo xx.

La teoría de la experiencia hermenéutica propuesta por el pensador alemán Hans-Georg Gadamer (1993) resulta pertinente para el análisis, en la medida en que aborda el fenómeno de recepción estética de forma por demás amplia y, aunado a ello, incorpora como objeto de análisis las expectativas ("prejuicios") de los potenciales lectores/espectadores. Se considera al texto como producto de su concreción histórica y única (Gadamer, 1993: 33), conscientes de que la comprensión es un proceso de producción de sentido en el que el tiempo juega un papel fundamental. En ese sentido, Pierre Sorlin coincide con Gadamer en la importancia del público para la clasificación y análisis de una película. En sus estudios sobre cine histórico Sorlin advierte que, la clasificación de una cinta como "histórica" está supeditada a que los propios espectadores la consideren tal, y establezcan una relación entre la diégesis y su historia cultural (2001: 25-49). En la misma línea, se retomará el concepto de horizonte de expectativas, enunciado por Robert Hans Jauss, que él define como "el sistema de relación objetivable de las expectativas que nace para cada obra de la comprensión previa del género, la forma y la temática de obras anteriormente conocidas y de la oposición entre lenguaje poético y lenguaje práctico en el momento histórico de su aparición" (Jauss, 2013: 177). El grado de cercanía de la obra a dicho sistema referencial marcaría el éxito o rechazo de la obra entre el público y los críticos, lo cual podremos ver para el caso de las obras Franz Werfel y Miguel Contreras Torres.

\section{El cataclismo austrohúngaro y sus autores}

El fenómeno cultural de la "Viena de fin de siglo" ha sido tema de muchos trabajos, tanto de manera general como centrados en 
personajes específicos que sobresalieron en la ola de virtuosismo que caracterizó la época. La vasta Austria-Hungría contó en su ocaso con innumerables ejemplos de talento en muchas áreas. Una de las más favorecidas fue la literatura, Joseph Roth, Karl Kraus, Hermann Broch, Franz Kafka, Robert Musil y Stefan Zweig son los autores más conocidos del periodo, sin embargo, a la par y en ocasiones de la mano, otros escritores desarrollaron prolíficas carreras. Es el caso de Franz Werfel, quien fue un escritor exitoso en su momento y cuya obra va de la poesía al drama, pasando por la novela.

El periodo de entre guerras fue difícil en Austria, que se enfrentaba a la mutilación de su otrora imperio y a una nueva dinámica política donde la monarquía quedaba atrás y surgían los proyectos democráticos. En ese marco, el teatro de larga tradición en Viena fue un gran vehículo de expresión para las nuevas ideas (de todo tipo) y para la crítica. Joshep Nadler aseguraba "que 'la tribu' austro-bávara tiene especial talento para el teatro, manifestado primero en el drama folclórico medieval y que alcanzó su punto más alto en la era barroca” (Beniston, 2006: 27). Los escritores se debatían entre el expresionismo representado por el famoso Arthur Schnitzler y respuestas de corto alcance a esta corriente; pero ante todo se evitaron el bolchevismo y las innovaciones en el montaje, mientras que se abordaban los temas citadinos, la clase media, y al mismo tiempo se recuperaba la literatura histórica y el folclor (Beniston, 2006: 28-31). Franz Werfel fue, en este contexto, un dramaturgo exitoso, que incluso mantuvo su fama después de su exilio en los Estados Unidos y hasta su muerte, el 26 de agosto de 1945.

Werfel nació en Praga, el 10 de septiembre de 1890, que en ese momento era parte de Bohemia, una de las provincias del Imperio Austro-Húngaro. Fue el mayor de tres hijos de un matrimonio judío-alemán. La situación económica de su familia le permitió vivir 
cómodamente durante su infancia al cuidado de una niñera, y después estudiar en un colegio católico privado. Fue un mal estudiante, lo que no impidió que siguiera sus estudios en el Stefansgymnasium de Praga. Ahí conoció a Willy Haas y Paul Kornfeld, quienes serían a su vez figuras del mundo literario praguense. Comenzó entonces su gusto por las sesiones espiritistas. Posteriormente se matriculó en la Universidad Alemana de Praga en donde tomó clases de leyes y filosofía. Sin embargo, nada de ello lo disuadió de convertirse en escritor para enojo de su padre, quien le consiguió un puesto aprendiz en una agencia de envíos de Hamburgo. Tras boicotear este intento, en 1911, Werfel realizó su servicio miliar en un regimiento de artillería; ese mismo año publicó su primer libro de poemas Der Weltfreund, con el que comienza su fértil carrera (Wagener, 1993: 2-5).

Si bien las primeras obras dramáticas de Werfel fueron sobre temas míticos, en una segunda etapa, marcada por el final de la Gran Guerra, su estilo se vuelve más realista y acorde con la Nueva Objetividad que invitaba a un lenguaje más sobrio (Wagener, 1993: 53-54). Precisamente para dotar a Juarez und Maximilian de mayor objetividad, el dramaturgo hizo un trabajo de documentación histórica, del que él mismo destaca las obras: Historia del reinado de Maximiliano I, La tragedia del emperador de México y Las anotaciones de un testigo presencial, de Ernst Schmitt Ritter von Tavera; Recuerdos de México, del Doctor Basch; Porfirio Diaz, de Alice Tweedi, ${ }^{2}$ y Maximiliano y Carlota de México, de Cesare Conte Corti. De este último afirmó: "ha llegado a ser preciosa para mí por su abundante material de cartas, documentos y citas" (Werfel, 2002: 131). No obstante, Juarez und Maximilian no intenta ser

${ }^{2} \mathrm{El}$ nombre que da Werfel es este, sin embargo, se puede suponer que se refiere a Alex Tweedie, viajera de las Islas Británicas quien conoció a Porfirio Díaz en persona y publicó su biografía en 1906 (Garner, 2014: 11). 
una recreación histórica detallada, su objetivo central es hacer una exposición de ideales y de caracteres.

Al respecto, John Warren y Hans Wagener coinciden en la existencia de una constante en los dramas que Werfel escribió hacia esos años; a saber, además de la aventura del Habsburgo en México, Paulus unter den Juden: dramatische Legende in sechs Bildern (1926), y Das Reich Gottes in Böhmen: Tragödie eines Führers (1930) (Wagener, 1993: 53-54). En los tres dramas se encuentra la idea de amor cristiano sintetizado en la frase "ama a tus enemigos". Pero los héroes no permanecen puros, sino que manchan sus manos de sangre y aceptan el peso de la culpa. La culpa finalmente tendrá consecuencias pues, afirma Warren, esta culpabilidad actúa a niveles sicológicos muy profundos afectando las acciones de sus personajes, los vuelve indecisos, problemáticos y con una extraña fascinación por el traidor (Wagener, 1993: 54).

El drama Juarez und Maximilian inicia cuando el Imperio Mexicano de Maximiliano y Carlota está ya instalado en la Ciudad de México y su rival, el presidente republicano Benito Juárez, se encuentra en Chihuahua. El ejército francés comandado por el Mariscal François Bazaine y el ejército imperial combaten al ejército republicano liderado por los generales Porfirio Díaz, Mariano Escobedo y Vicente Riva Palacio. El tiempo pasa, el dinero se agota y Maximiliano ve cada vez más frágil su posición de Emperador. Entretanto, Juárez le devuelve a Maximiliano el retrato que este le había mandado con la frase "El objeto de la enemistad es la reconciliación” (Werfel, 2002: 16). Al Emperador esto lo impresiona tanto que firma un decreto de fusilamiento a los republicanos que antes había rechazado. Carlota, quien lo animó a cruzar el océano, lo apoya y finalmente regresa a Europa a implorar la ayuda de Francia y Roma. Los triunfos republicanos y la lealtad y valentía de Porfirio Díaz arrinconan al Emperador quien, pese a los consejos, permanece en México, acompaña a su ejército a Querétaro 
y enfrenta una condena similar a la que él mismo firmó: fusilar a los enemigos que sean capturados. Los intentos por salvar su vida son en vano, Juárez es un hombre implacable que en la escena final llegará a Querétaro únicamente para corroborar la muerte de Maximiliano y el final del Imperio.

Desde el estreno del montaje teatral, realizado en el teatro Josefstadt en 1925, se manifestaron las lecturas políticas e ideológicas que la obra podía provocar, mismas que se analizarán más adelante. Aunque Juarez und Maximilian fue un éxito en su momento y la crítica hizo comentarios positivos sobre la obra, otorgándole incluso el premio Grillparzer de la Academia de Ciencias de Austria en 1926, a la larga no es uno de los trabajos más reconocidos de Werfel.

\section{La primera superproducción nacional}

La política cultural del México posrevolucionario fue abiertamente nacionalista desde sus primeros ańos; como lo demuestran los acalorados debates sobre la identidad mexicana, el interés por establecer una mitología revolucionaria y los trabajos para ampliar la educación y mejorar su calidad. ${ }^{3} \mathrm{Al}$ mismo tiempo, el ambiente cosmopolita de la Ciudad de México se remarcó después de la guerra; la aparición de nuevos medios de comunicación permitió que las noticias y novedades de Europa y Estados Unidos se hicieran cada vez más presentes en la ciudad. Parte importante de ese cosmopolitismo se debió al interés de las élites intelectuales que hablaban varios idiomas y habían viajado a diferentes ciudades del mundo. Entre estos intelectuales se encontraba Salvador

${ }^{3}$ Sobre los constantes debates sobre las relaciones entre historia, patria, nación, arte y educación existen numerosos estudios entre los que destacan los incluidos dentro de la colección Sepsetentas y otros posteriores Vázquez, 1975; Fell, 1989; Fabián Mesta, 2016; Benjamin, 2003. 
Novo quien, durante el tiempo que estuvo a cargo de la Editorial de "La Razón", procuró la traducción y publicación de literatura extranjera. ${ }^{4}$ Una de las obras seleccionadas por Novo para esto fue Juarez und Maximilian, que fue publicada en 1931 con el título Juárez y Maximiliano. Inmediatamente la "Revista de la Universidad de México" publicó una breve reseńa de Baltasar Dromundo, favorable a la obra, y alabó la traducción de Enrique Jiménez Domínguez:

Los actos de esta obra teatral son de un dramatismo puro y conmovedor. Salvo alguna elasticidad histórica, la obra en total es magnífica. La acción, los acontecimientos y especie de fuerza inevitable e inescrutable que rige el destino de los hombres, conceden a la obra una categoría dramática muy valiosa.

La traducción de algunos cuadros nos parece tan castiza, tan pulida y hecha con tan buen afán, que ha resultado un perfecto trabajo (Dromundo, 1931: 440).

Paralelamente, a inicios de la década de los treinta el cine producido en México inicia su despegue, para conformarse como industria en la segunda mitad de la década. Santa, producida en 1931, marcó el inicio del cine mexicano sonoro que comenzó a producirse rápidamente en mayor cantidad. ${ }^{5}$ Para ese momento, Miguel Contreras Torres era ya un conocedor del medio. Proveniente de una familia de pequeños hacendados de Michoacán, se

${ }^{4}$ Novo estuvo bajo las órdenes del Dr. José Manuel Puig Casauranc. Esta editorial contó con el patrocinio del Dr. J. Gastélum; además de la obra que nos ocupa se tradujeron La conversación, de André Maurois, y La escuela de las mujeres, de André Gide (Barrera, 1999: 181).

${ }^{5}$ La primera película sonora realizada en México fue Contrabando, filmada en Tijuana, pero esta se estrenó hasta cinco meses después que Santa, que lo hizo en octubre de 1932 (Castro Ricalde, 2011: 20). 
enlistó muy joven en las filas carrancistas bajo el mando del general Alfredo Elizondo, alcanzando el grado de Mayor. Al dejar el ejército, se dedicó junto con sus hermanos a la exhibición de películas en Morelia; posteriormente, se mudó a Hollywood y comenzó a hacer pequeños trabajos detrás de cámaras y apariciones breves en pantalla. Volvió a México con todo el conocimiento adquirido y filmó su primera película muda: "De raza azteca” (1921), con la colaboración de otro pionero del cine mexicano Guillermo "El Indio" Calles (Ciuk, 2009: 175-176). Inicia con ello su carrera como productor, director y actor, pues en varias ocasiones sería el protagonista de sus propias cintas. En 1933 contaba ya con 14 películas que, pese a no haber sido del todo exitosas, lo mantenían como un personaje importante del medio cinematográfico mexicano.

La carrera como director y productor de Contreras Torres tendría uno de sus puntos más altos entre 1933 y 1934, gracias a la filmación de "Juárez y Maximiliano. La caída del imperio". Para dicho proyecto había conseguido recursos y facilidades que le permitieron realizar la primera superproducción mexicana. El director afirmó que el presupuesto del que dispuso para la filmación fue de quinientos mil pesos; por única vez, para su pomposo estreno, se dispuso del Palacio de Bellas Artes y permaneció en cartelera por seis semanas (Ramírez, 1994: 42). Otro indicio de su éxito es el hecho de que no fuera exhibida en cines de segunda categoría, más económicos, lo que provocó la queja del público y discusiones en la prensa por lo costoso de los boletos. ${ }^{6}$ En realidad, los temas históricos y especialmente nacionalistas fueron preferidos desde un inicio por Contreras, que a la postre se consolidaría como el

${ }^{6} \mathrm{El}$ costo de la entrada fue de 3 pesos mientras que en los cines de segunda línea podía ser de cincuenta centavos. Cineteca Nacional, Expedientes Hemerográficos, A-03058, Juárez y Maximiliano, ff. 200-202. 
productor y director de cine histórico por excelencia durante la primera mitad del siglo xx en México.

La película "Juárez y Maximiliano" inicia con la llegada de los Emperadores Maximiliano y Carlota a la Ciudad de México, el Te Deum solemne por su llegada y la recepción en Palacio Nacional. En seguida vemos a Porfirio Díaz en su cuartel general recibiendo órdenes del presidente Benito Juárez. Maximiliano y Carlota en Chapultepec, el Emperador habla con Bazaine sobre la situación de la guerra, y Juárez por su parte anda en el campo en su diligencia. Carlota se entera de la falta de dinero y de la muerte de su padre el Rey Leopoldo. Maximiliano recibe de vuelta un retrato suyo con la frase "La enemistad es la sabiduría de la reconciliación", que le había enviado a Juárez en señal de reconciliación; al mismo tiempo, Bazaine lo insta a que firme el decreto para fusilar a todos los rebeldes y él lo firma. Carlota parte a Europa. Un representante de Maximiliano intenta ganar para su causa a Díaz, que se encuentra prisionero, pero este lo rechaza y se fuga en forma espectacular. Maximiliano se entera del mal estado mental de Carlota, se anuncia su intención de abdicar y la Junta de Notables rechaza la abdicación. Maximiliano decide ir a Querétaro. López entrega el cuartel general a los republicanos, apresan a Maximiliano, la princesa de Salm-Salm planea su fuga con ayuda del doctor Basch pero el plan fracasa. En San Luis Potosí nuevamente la princesa de Salm-Salm intenta salvar la vida de Maximiliano implorando a Juárez, quien no accede. Mejía y Miramón hacen creer al emperador que Carlota ha muerto, los tres son fusilados.

"Juárez y Maximiliano" fue una gran apuesta por el cine sonoro nacional, por la posibilidad de crear una industria cinematográfica. Pese a ello recibió críticas duras respecto a la forma en la que se trataba a los personajes históricos, y no pasaron desapercibidas las similitudes con la obra homónima escrita por Werfel. En los créditos de la cinta Contreras aparece como único autor, no menciona 
la obra austriaca. ¿Se trataba de una casual coincidencia de títulos? Agudamente, Contreras omitió cualquier referencia a sus fuentes, y se erigió como único autor del "fotodrama histórico", reconociendo únicamente la labor de corrector de estilo en diálogos a Francisco Monterde García Izcabalseta [sic], escritor y académico.

Conscientes de las conexiones que fácilmente se harían entre la obra de Werfel y la película, Columbia Pictures, quien realizó la distribución de la cinta a nivel mundial, se esmeró en desmentir cualquier relación más allá del título, pues aseguraba que la trama era diferente a pesar de tratarse de los mismos personajes. ${ }^{7}$ Resalta que todos los personajes que aparecen en los créditos de la cinta están también en la obra teatral, aunque en el drama hay algunos más; esta coincidencia, fácil de verificar, junto con su título, es el primer indicio de la influencia de la obra austriaca en la película.

Si bien existen diferencias entre el drama y la película, también es cierto que el director mantiene varios aspectos de la obra de Werfel; los fundamentales son los personajes y su carácter, que confieren a la trama su sentido y justificación. En ambas obras, Maximiliano se nos presenta como un hombre gentil y de buena voluntad, que quizá ha querido ser engańado pero que al final de su aventura acepta su muerte con la resignación propia de quien se

7 "La película lleva el nombre de Juárez y Maximiliano, mismo que tiene la obra teatral de Franz Werfel, pero solo en el título hay semejanzas, porque la trama es diferente, aun cuando intervienen los mismos personajes, pero ello se debe a que fueron los protagonistas de los sucesos que acaecieron en la época que se ha llevado a la pantalla. A este respecto, la Columbia Pictures, compañía que ha tomado a su cargo la distribución mundial de la sensacional cinta, nos suplica que hagamos la aclaración de que 'Juárez y Maximiliano' o 'La caída de un Imperio', obra cinematográfica que será estrenada mañana jueves, no tiene relación en lo absoluto con la obra de Franz Werfel, cuya traducción hizo el señor licenciado Enrique Jiménez D." (Cineteca Nacional, Expedientes Hemerográficos, A-03058, Juárez y Maximiliano, "Mañana se estrenará "Juárez y Maximiliano", f. 198). 
reconoce como culpable y merecedor a un castigo. Para Julia Tuñón, el Maximiliano de Contreras es un héroe de "valores calientes”, de acuerdo con la distinción entre valores calientes y valores fríos propuesta por Claudio Magris (Tuñón, 2010: 90). Así, las virtudes calientes, son aquellas relacionadas con el mundo emotivo: el erotismo, el amor, la religión o el arte. Por su parte, Benito Juárez estaría relacionado con los valores fríos de carácter cívico; las leyes y la democracia, por ejemplo.

Pero Juárez está ausente en el drama, o casi ausente en la película, aunque se mantiene como una presencia permanente en la mente de Maximiliano, Díaz y todos los demás personajes. Incluso, pese al desenlace fatal, Juárez no representa un verdugo sanguinario, sino un defensor de las leyes y la justicia, eso sí, implacable. Por otro lado, también en ambos casos Porfirio Díaz encarna al héroe de epopeya, que va al mando de las tropas y hace gala de destreza física, pero al mismo tiempo respeta a Maximiliano. En ambas obras Bazaine y Napoleón III son los traidores, verdaderos villanos del drama histórico en el que Maximiliano se ve envuelto.

El cambio más importante entre las obras de Werfel y Contreras está en el personaje de Carlota. Si Werfel le confiere un aura maternal remarcada por la adopción del pequeño príncipe Agustín de Iturbide, Contreras la convierte en toda una estadista que hace pase de lista a su guardia y atiende asuntos económicos con el consejo imperial. Las diferencias en el personaje probablemente estuvieron motivadas por Medea de Novara, la actriz que encarna a Carlota y que era esposa de Miguel Contreras, originaria de Liechtenstein. El cineasta mexicano intentó explotar las similitudes entre Carlota y su esposa como parte de la campańa publicitaria de la película y de otra posterior, "La paloma” de 1937, en la que reutilizó parte del material filmado en 1933. En el fondo lo que intentaba era transformar a Medea en una estrella de cine. 
Es en ese tenor que Carlos Noriega Hope "revela" a un periodista el supuesto origen noble de Medea, de la que sin embargo no quiso revelar su verdadero nombre. De acuerdo con Noriega, Medea de Novara era en realidad una duquesa emparentada con los Habsburgo, que había sido despreciada por su familia debido a que "su sueño fue ser artista de cine, y en esa rama deseó siempre llevar a la hoja de plata a Carlota Amalia, Emperatriz de México, por la que ha cultivado una especie de veneración". ${ }^{8}$ Así en "Juárez y Maximiliano" confluyen tanto el afecto de Novara por Carlota, como la pasión de Contreras por la historia de México; de esta forma podemos entender que el productor pusiera tanto esfuerzo en el proyecto, aunque sus temas predilectos fueran la lucha por la independencia y la revolución, como lo demuestra su filmografía.

\section{Cruces entre México y Austria}

Se han presentado las características de dos obras y dos autores que se insertan en contextos alejados en el espacio y el tiempo, y que no obstante coinciden en líneas de pensamiento y temas de interés que se pueden ubicar dentro de una tradición. De inicio se puede señalar el gusto por la Historia que Werfel y Contreras Torres mantienen a lo largo de sus obras; en ese sentido, resalta la proclividad a usar el arte como medio para transmitir sus ideas sobre la historia. Ambos mantuvieron la conciencia de ser parte de un momento histórico importante, el austro-húngaro en la Primera Guerra Mundial y el mexicano en la revolución civil; además, profesaron un catolicismo militante, más llamativo en el caso de Werfel por ser judío de nacimiento; finalmente, buscaron una postura

${ }^{8}$ Cineteca Nacional, Expedientes Hemerográficos, A- 03058, Juárez y Maximiliano, "Medea de Novara, protagonista en la película "Juárez y Maximiliano", que desciende de antigua familia vienesa, emparentada con los Hapsburgo [sic]", f. 199. 
política entre el conservadurismo y las nuevas formas de gobierno. En esto último, la postura de Werfel fue sin embargo más radical, pues abrazó por varios años un socialismo militante que lo llevó a formar parte de la Guardia Roja, aunque su inclinación era pacifista (Wagener, 1993: 7). Los dos expresan evidentemente credos políticos e interpretaciones históricas coincidentes, en el caso de Juárez y Maximiliano respaldada por una investigación histórica, como se remarca tanto en el libro de Werfel como en la publicidad de la película de Contreras Torres.

Franz Werfel fue uno de los principales voceros de la ańoranza imperial austro-húngara, un sistema referencial compartido con un importante sector del público y la crítica. Para Claudio Magris, "La obra de Werfel constituye la ficha ideal del mito habsbúrgico [...] celebra sus tres componentes principales: la idea supranacional, la estática y grandiosa mediocritas, el gozoso hedonismo" (1998: 424). Y, sin embargo, también fue un opositor a la instalación de una monarquía tras la disolución del imperio (Lützeler, 1989: 60-62). Si preguntamos por la intención de Werfel al escribir Juarez und Maximilian debemos retomar la teoría de la recepción de Hans Gumbrecht para preguntarnos por las relaciones funcionales e históricas que el autor encontró con los interlocutores de la Viena de 1924-25. ' La elección del tema y la escritura del drama pudieron estar relacionados con la muerte del Emperador Carlos

\footnotetext{
${ }^{9}$ Esto de acuerdo con la teoría literario-sociológica de la recepción que postula como necesario, para realizar interrogantes y comprender las respuestas, "fundamentar tanto social-histórica como ideológica-críticamente con respecto a las anteriores relaciones e intereses de las capas del lector y de la formación, así como también se pueden agotar funcional-históricamente, con miras a las normas estéticas y a la necesidad imaginativa de generaciones cambiantes del público" (Gumbrecht, 2008: 238).
} 
I, ${ }^{10}$ sobrino-nieto de Maximiliano, pues podían establecerse similitudes entre el rechazo a la abdicación por parte de Maximiliano y su aceptación por parte de Carlos (Beniston, 2006: 42). La obra es realmente un manifiesto que explica la postura de Werfel respecto a la monarquía, los Habsburgo, el carácter austro-húngaro y la democracia, dentro de un horizonte de expectativas compartido por los austriacos en ese momento.

De acuerdo con la prensa en la Viena de 1925, cuando se montó la obra, la recepción del público fue buena. Se publicaron críticas sobre el drama que ahondaron en la representación del "austriaco" que hacía el autor, y donde se hizo explícita la analogía entre Carlos y Maximiliano. La indagación sobre el contexto de recepción nos arroja a esta primera discusión. Gracias al trabajo de Robert Pyrah, podemos recuperar parte del ambiente sumamente politizado de la Viena de los veintes. La prensa de la época revela discusiones del público intelectual que permiten advertir una opinión dividida, el Maximilian de Werfel, ¿se trata de una caracterización del austriaco, o específicamente del monarca Habsburgo?

Joseph Gregor llamó al Maximiliano de Werfel la "completa realización del hombre austriaco" y a la obra un "genuinamente patriótico, drama austriaco". ${ }^{11}$ A lo largo del drama, Maximiliano se convierte en el arquetipo del austro-húngaro. El propio Maximiliano echa en cara a un paisano que los austriacos son "pedantes, melancólicos [...] siempre anhelando hallar pelos en la sopa”

${ }^{10}$ Carlos I de Austria y Iv de Hungría fue el último emperador de Austria-Hungría, heredó el trono de Francisco José a la muerte de este en 1916, en medio de la Primera Guerra Mundial. Tras perder la guerra en 1918 el imperio se disolvió y Carlos renunció a su cargo y cualquier posibilidad de gobernar Austria, manteniendo sus títulos. En 1921 intentó recuperar el trono de Hungría mediante un golpe de estado fallido. Finalmente murió en Portugal en 1922.

${ }^{11}$ En un ensayo publicado en el programa de la producción del teatro Josefstatd en 1925 (Pyrah, 2007: 141). 
(Werfel, 2002: 27). Un reclamo a sus paisanos. No obstante, la marca más contundente en Maximiliano será la culpa, "una culpa bien austriaca" como llama el doctor Basch "al desesperado optimismo frente a lo incierto y a la huida antes de reconocer lo desagradable" (Werfel, 2002: 56-57), que son características de la personalidad del Emperador.

Por otro lado, de acuerdo con Claudio Magris, Maximiliano es la representación de los valores de los Habsburgo: "Aunque realmente el derecho está del lado de Juárez, Maximiliano tiene, como el inocente sacrificado del último sueño imperial, el derecho en el sentido más íntimo" (Pyrah, 2007: 141). Los Habsburgo están marcados como las víctimas propicias para el sacrificio, su destino fue ser la ofrenda que marcó la muerte del mundo imperial. Maximiliano confiesa por todo su linaje "creí y sigo creyendo que la monarquía legítima, liberal y progresista como yo la quería, podría salvar a este país de las luchas políticas" (Werfel, 2002: 87). Para Werfel, Juárez representa a la tiranía, en el sentido que le da Aristóteles: concentración del poder en una sola persona, el tirano. El tipo de tiranía que el austriaco quiere ver en México sería aquella que surge de una democracia más radical, producto del exceso de pobreza, sostenida por el pueblo y que "hace la guerra a los notables" (Aristóteles, 1988: 334).

Las lamentaciones sobre el fin de la monarquía se observan en un texto publicado en el Neue Freie Presse con motivo del estreno:

¿Acaso no tenemos a los Habsburgo, quienes nos gobiernan y quieren hacernos felices, experimentamos su incapacidad para gobernarnos o incluso para hacernos felices? Pobre Karl, ahogado entre la miseria por la confusión de Europa y de sus monarquías, quienes fueron casi mexicanos en carácter [...] La idea de hacer que el Emperador perdiera contra un enemigo invisible, esta valiosa y poética idea, podría solo tener origen después de la expe- 
riencia de años de tumultos políticos donde la monarquía colapsó (Pyrah, 2007: 142).

Mas allá del patetismo y la melancolía, David Josef Bach señala que el final trágico de Maximiliano responde a los necesarios caminos de la historia, ${ }^{12}$ y Werfel lo muestra tal cual, por eso Juárez no es cruel ni sanguinario, sino únicamente un político que actúa de acuerdo con lo que la Historia necesita. Existe en Werfel una filosofía de la historia con alcances metafísicos, los acontecimientos ocurren a pesar de la acción humana, a causa de una fuerza superior que los determina. Así lo expresó también en otros trabajos en donde existe una causa metafísica superior para todos los problemas (Wagener, 1993: 138-139). Es preciso recordar que, desde sus sesiones espiritistas de juventud, el praguense siempre mantuvo un fuerte interés en la religiosidad y la espiritualidad que se reflejó en la mayoría de sus trabajos (Hartmann: 1998).

En contraste, el México de la década de los treinta se encontraba llegando a la cresta de la ola de la transformación. Los combates de la revolución habían dejado lugar a la creación de las instituciones, y la paz se sentía ya como algo cotidiano, al tiempo que la modernidad se asomaba en las crecientes ciudades del país. Sin embargo, las disputas habían pasado al ámbito intelectual, en donde uno de los grandes temas sería el de la historia patria y el acomodo de los recientes acontecimientos a su narrativa. En un país con un alto nivel de analfabetismo, el cine se convirtió pronto en una herramienta para la difusión de ideas e ideologías. Miguel Contreras Torres estaba convencido de esto, así como de que el Estado debía

${ }^{12}$ En su análisis, Bach agrega también una identificación de clases dentro de la obra, los proletarios están representados por Porfirio Díaz, como modelo de ascenso exitoso por la lucha, mientras Bazaine es ejemplo de un proletario que ha perdido su identificación de clase debido a un ascenso dentro del sistema (Pyrah, 2007: 143). 
tomar parte en este trabajo. Así lo aseguró en El libro negro del cine mexicano, existen "ciertas obligaciones de orden histórico y social" (1960: 15) que el cine debería cumplir con apoyo del gobierno.

El periodo que los historiadores denominan Intervención francesa o Segundo Imperio es parte de esta Historia, una parte muy controversial pues toca los delicados hilos del nacionalismo y el liberalismo. Benito Juárez es el gran héroe del periodo, según el mito liberal, y así queda demostrado en los discursos cívico-patrióticos oficiales. No obstante, los grupos conservadores, legítimos herederos de los artífices del Segundo Imperio, han mantenido desde un inicio la figura de Maximiliano como víctima de las disputas políticas del país. En este marco, Contreras Torres se arriesga a la crítica y lo hace desde el conocimiento de que su cinta pone como protagonista al rival del héroe liberal mexicano por excelencia.

Los críticos advirtieron inmediatamente cierta simpatía inapropiada en "Juárez y Maximiliano". Si bien la crítica cinematográfica Luz Alba ${ }^{13}$ resalta los alcances técnicos y la producción de la película, también comenta:

¿Por qué Contreras Torres quiso hacer la exaltación del imperio en vez de hacer la de Juárez, Díaz y los mexicanos que lucharon hambrientos, sin armas y cubiertos de harapos? Pues tal como plantea los hechos, el fusilamiento de Maximiliano no solo no se justifica, sino que se convierte en un acto de implacable crueldad de Juárez. Y tanto es así que los espectadores se vuelven partidarios del Emperador. ${ }^{14}$

${ }^{13}$ Seudónimo con el que la escritora Cube Bonifant solía firmar sus críticas (Mahieux, 2014: 38-40).

${ }^{14} \mathrm{CN}$, Expedientes hemerográficos, A-03058, Juárez y Maximiliano, "Testimonios. Luz Alba en El ilustrado, México, D.F., julio de 1934”, f. 194. 
Un ejemplo de esta visión positiva en la cinta es la escena en la que Maximiliano ordena la liberación de los presos políticos de la Ciudad de México, misma que Carlota aplaude añadiendo: "Tienes muchas cualidades Maximiliano, pero tu bondad es la mayor de ellas". Esta escena no aparece en el drama, en el que por otro lado aparece un largo discurso en defensa de los indios.

No obstante, es el primer discurso de Maximiliano en Palacio Nacional el que mueve más a simpatías. En él declara su pensamiento político y su religiosidad, simplificando las circunstancias en las que se ha convertido en Emperador:

Los pueblos no se han hecho para los soberanos, sino los soberanos para los pueblos. El pueblo en masa no tiene inteligencia sino instinto, y este instinto es siempre justo. Esta noble nación me ha pedido que la gobierne con las bendiciones del cielo, y con ellas el progreso y la libertad. Ya sabéis cuál es mi lema: imparcialidad en la justicia.

A la Emperatriz corresponde la noble tarea de cuidar al país y ayudar con los nobles sentimientos de una cristiana, y el cariño de una madre. Unámonos para alcanzar este fin común, sepultemos los odios de partido, que la aurora de la paz y de la felicidad renazca radiante sobre el nuevo imperio.

Maximiliano justifica su presencia en México como un deseo del pueblo mexicano, con la bendición del cielo asegurando que su reinado será ante todo justo, esto no va a ser matizado en la cinta, no vemos el contrapunto republicano que legitima al presidente Juárez. En este discurso, el director apela a la religiosidad del público mexicano, de una larga tradición católica, a la figura de la madre -Carlota-, a los principios de justicia y libertad, y finalmente a la idea de progreso; todo esto parte fundamental de las aspiraciones y valores de la sociedad de la época. 
Otro artículo crítico a la película apareció en El Universal poco después de su estreno, en él se critica: "la velocidad con que aparece Juárez, el escaso estudio de aquel carácter, que la filosofía de la historia ha profundizado, y que merecía una pintura más completa y detenida" ${ }^{15}$ En la cinta, Juárez solo aparece en dos escenas, ${ }^{16}$ una en la que aparece descansando en el campo y, la más extensa, en donde escucha los ruegos de la princesa de Salm Salm para que indulte a Maximiliano. Es decir, la escena en el que se niega a perdonar la vida del austriaco diciendo "no podría perdonarle la vida, no soy yo quien se la quita son...el pueblo y la ley".

Julia Tuñón analiza a la distancia la incompatibilidad del Juárez de Contreras Torres y el ícono patriótico, pues

la figura de Juárez se asocia primordialmente a la defensa contra el invasor extranjero, a la consolidación del Estado, al liberalismo político y económico, a la separación de la Iglesia y el Estado, a la secularización de los bienes de la Iglesia y a su condición racial de indígena. Todos estos aspectos adquieren un aroma mítico al referirse a sus orígenes y aparecen en la narración que cuenta la construcción de la nación moderna y en la enseñanza de la historia (Vázquez, 2010: 114).

Podemos observar que esto no es lo que se enaltece en la película. En ese sentido, la narrativa cinematográfica de Contreras sustituye los discursos de los liberales por acciones; por ejemplo, nunca vemos una declaración de principios de Juárez, ni alguna explicación de los acontecimientos que llevaron al enfrentamiento

${ }^{15} \mathrm{CN}$, Expedientes hemerográficos, A-03058, Juárez y Maximiliano, “3 de julio de 1934. El Universal. Crítica de L. de L.”, f. 210.

${ }^{16}$ Una tercera sería la imagen fija del monumento en su honor ubicado en la Alameda central de la Ciudad de México, conocido como Hemiciclo a Juárez, la cual parece al final de la cinta. 
entre imperialistas y republicanos, pero sí nos presentan el escape de Díaz y numerosas escenas de batallas y caballería. Las razones y causas republicanas no se conocen, solo se puede observar sus acciones.

Respecto a la interpretación histórica del fusilamiento de Maximiliano, la cinta tampoco se aleja de la obra dramática. De forma menos ambigua, el propio Emperador lo expresa con resignación: “mi destino está escrito asî". Su destino es servir a México con el sacrificio de su vida, como un mártir necesario que espera la recompensa en el cielo, así se lo confirma al general Mejía frente al pelotón de fusilamiento:

General, lo que no premia Dios en la tierra lo premia en la gloria. Voy a morir por una causa justa, la de la libertad y la independencia de México, que mi sangre selle las desgracias de mi nueva patria.

De esta forma Juárez se convierte en un justiciero implacable e inflexible pero necesario, como lo comenta la crítica, el Maximiliano de Contreras es más una víctima de Napoleón III y el mariscal Bazaine que un villano, como lo presenta el mito oficial projuarista. Incluso disminuye la consciencia de culpabilidad en la que Werfel había hecho hincapié. A diferencia de la cinta, en el drama Maximiliano le dice al doctor Basch antes de su ejecución:

Ahora como hombre desligado de todo, sin rango ni prejuicios me doy cuenta, es mi culpa no estar a la altura de los propios actos. ¡El fracaso es culpa! La voluntad de ser bueno no llega a ser bondad. Mi concepto de una monarquía radical era falso. Así que la falla, la mentira tiene que radicar en mí ¡Culpa! Ha pasado la época de los soberanos. En el naufragio de las clases privilegiadas 
se debaten reyes lastimosos que no lo son. Se inicia la era de los dictadores ¡Juárez! (Werfel, 2002: 120).

Tenemos en Werfel un antimonárquico no porque abomine de la institución, sino porque la considera inadecuada para el mundo en el que vivía. Y va más allá, al declarar la analogía con el Imperio Austrohúngaro y su inevitable caída aun cuando el mismo escritor lo recuerde con nostalgia:

Y a pesar de todo, no me parezco a ti, Francisco José. Todos ustedes fueron desertores ante su destino. Yo acepté el mío. Hubiese podido desertar, pero no me fue posible. Esa culpa también tiene que radicar en mí. Usted lo sabe Basch, fui a Querétaro a sabiendas, debía hacerlo, de la misma manera que López debía traicionarme (Werfel, 2002: 120).

Maximiliano representa el tipo ideal del austrohúngaro, como se mencionó en su momento, no de los Habsburgo, porque hubo otros Habsburgo que se resistieron a aceptar su inevitable caída.

Además del tono proimperialista se pudo advertir otro aspecto controversial: la importancia y protagonismo de Porfirio Díaz, verdadero héroe de acción. Así lo señalan en otra nota periodística:

En esta película aparecen personajes importantes en nuestra historia: Benito Juárez, el Benemérito de las Américas, figura solamente en tres escenas, en cambio, el general Porfirio Díaz aparece en la pantalla varias veces, y se ve su sensacional fuga de la prisión en Puebla, escalando muros. ${ }^{17}$

${ }^{17} \mathrm{CN}$, Expedientes hemerográficos, A-03058, Juárez y Maximiliano, "El día 28 se estrena "Juárez y Maximiliano", f. 196. 
Es decir, la película resalta el heroísmo y las virtudes de Díaz, cuya posterior dictadura provocaría la guerra civil que llamamos revolución mexicana. Esto es especialmente contradictorio si recordamos que Contreras Torres había participado en la lucha revolucionaria. De hecho, él era parte de la Legión de Honor y del Cuerpo de Veteranos, e incluso era amigo de muchos de los políticos emanados de la guerra que llegarían a ser gobernadores y presidentes; precisamente gracias a estas amistades, Contreras había logrado el apoyo económico, material y logístico para su superproducción.

\section{Conclusiones}

Existen similitudes entre Franz Werfel y Miguel Contreras Torres, no obstante, son aún más sus diferencias, tan grandes como las circunstancias que los rodearon, y a pesar de ello coinciden en su representación de Maximiliano como una víctima o, en términos cristianos, un mártir sacrificado. En cuanto a su recepción, Juarez und Maximilian no fue tan controversial en su momento como lo fue "Juárez y Maximiliano", pues no contrario los juicios e ideas que se tenían sobre la monarquía, e incluso fue un reflejo de los sentimientos que los austro-húngaros nostálgicos tenían hacia el extinto imperio. El drama de Werfel expresa reconocimiento al imperio habsbúrgico en el que creció y da una explicación a su final, pero no propone su retorno. Por su parte, la cinta de Contreras contraviene la narrativa oficial y busca crear simpatías en el espectador hacia Maximiliano y el imperio, quienes de acuerdo con el nacionalismo del momento deberían ser el enemigo. Por ello se considera que Werfel coincidió más profundamente con el horizonte de expectativas en el que se desenvolvió, mientras que Contreras Torres encontró una crítica fuerte entre los analistas que no compartían su interpretación. 
El apoyo gubernamental recibido para la filmación revela el reconocimiento a la calidad y conocimientos del michoacano, sin embargo, también evidencia una falta de interés en controlar los relatos de la historia patria por parte del Estado mexicano. El éxito que tuvo "Juárez y Maximiliano" entre el público revela la aceptación de las ideas monarquistas entre los mexicanos, particularmente entre la naciente clase media y alta, puesto que los boletos tenían un costo elevado. Finalmente, el deseo de tener una industria cinematográfica nacional permitió que las implicaciones ideológicas fueran relegadas y Juárez y Maximiliano fuera juzgada en su momento como una gran película, alabada por sus alcances y técnicos y artísticos.

\section{Bibliografía}

Aristóteles, 1988, Politica, Manuela García Valdés (intro., trad., y notas), Editorial Gredos, Madrid.

Beniston, Judith, 2006, "Drama in Austria, 1918-1945", en Katrin Kohl y Ritchie Robertson, A history of Austrian literature 1918-2000, Camden House, Estados Unidos, pp. 21-52.

Benjamin, Thomas, 2003, La revolución mexicana. Memoria, mito e historia, María Elena Madrigal Rodríguez (trad.), Taurus, México.

Castro Ricalde, Maricruz y Robert McKee Irwin, 2011, El cine mexicano "se impone". Mercados internacionales y penetración cultural en la época dorada, Universidad Nacional Autónoma de México, Coordinación de Difusión Cultural, México.

Ciuk, Perla, 2009, Diccionario de directores del cine mexicano 2009, t. 1, Consejo Nacional para la Cultura y las Artes, México.

Contreras Torres, Miguel, 1960, El libro negro del cine mexicano, Editora Hispano-Continental Films, México. 
Dromundo, Baltasar, 1931, "Juárez y Maximiliano", Revista de la Universidad de México, núm. 11, septiembre de 1931, México, p. 440 .

Fabián Mesta, Graciela, 2016, Historia patria y educación en la formación de la nación mexicana. La Ciudad de México como ensayo de reformas, segunda mitad del siglo XIX, Instituto Nacional de Antropología e Historia / Escuela Nacional de Antropología e Historia, México.

Fell, Claude, 1989, José Vasconcelos. Los años del águila (19201925). Educación, cultura e iberoamericanismo en el México postrevolucionario, Universidad Nacional Autónoma de México, México.

Gadamer, George, 1993, Verdad y método, t. 1, Ana Agud de Aparicio y Rafael de Agapito (trad.), Sígueme, Salamanca.

Garner, Paul, 2014, Porfirio Diaz Profiles in Power, Routledge, Estados Unidos.

Gumbrecht, Hans Ulrich, 2008, "Sociología y estética de la recepción”, en En busca del texto. Teoría de la recepción literaria, Dietrich Rall (comp.), Universidad Nacional Autónoma de México / Instituto de Investigaciones Sociales / Centro de Enseñanza de Lenguas Extranjeras, México, pp. 223-214.

Hartmann, Volker, 1998, Religiosität als Intertextualität. Studien zym Problem der literasrischen Typologie im Werk Franz Werfels, Gunter Narr Verlag Tübingen, Alemania.

Jauss, Robert Hans, 2013, La historia de la literatura como provocación, J. Godo Costa y J.L. Gil Aristu (trad.), Gredos, Madrid.

Lützeler, Paul M., 1989, Hermann Broch. Una biografía, Edicions Alfons El Magnanim, IVEI, Valencia.

Lowith, Karl, 2007, Historia del mundo y salvación. Los presupuestos teológicos de la filosofía, Norberto Espinoza (trad.), Katz, Buenos Aires. 
Magris, Claudio, 1998, El mito habsbúrgico en la literatura austriaca moderna, versión de Guillermo Fernández, Universidad Nacional Autónoma de México, México.

Mahieux, Viviane, 2014, "Cube Bonifant. Una vida en la prensa", Letras libres, núm. 186, junio, pp. 38-40.

Ramírez Aznar, Gabriel, 1994, Miguel Contreras Torres, 18991981, Centro de Investigación y Enseñanza Cinematográficas / Universidad de Guadalajara, México.

Pyrah, Robert, 2007, The Burgtheater and Austrian Identity; Theater and Cultural Politics in Vienna 1918-1938, Legenda, Gran Bretaña.

Sorlin, Pierre, 2001, "How to Look at an "Historical" Film", en Marcia Landy, The Historical Film. History and Memory in Media, Rutgers University Press, Nueva Jersey, pp. 25-49.

Tuñón, Julia, 2010, "Juárez y Maximiliano. Dos caras de una moneda en el imaginario fílmico del cine clásico mexicano", en Josefina Zoraida Vázquez, Juárez: Historia y mito, El Colegio de México, México, pp. 113-137.

, 2010, "Juárez y Maximiliano como modelos de nación", en La ficción de la historia. El siglo XIX en el cine mexicano, Ángel Miquel (coord.), Cineteca Nacional, México, pp. 90-105.

Vázquez, Josefina Zoraida, 1975, Nacionalismo y educación en México, El Colegio de México, México.

Wagener, Hans, 1993, Understanding Franz Werfel, University of South Carolina, Columbia, Estados Unidos.

Werfel, Franz, 2002, Juárez y Maximiliano, Elvira Martín y Annie Reney (trad.), Factoría Ediciones, México.

1951, El crepúsculo de un mundo, versión de Juan José Permanyer e Ignacio Rived, Luis de Caralt Editor, Barcelona. 
White, Hayden, 1992, Metahistoria. La imaginación histórica en la Europa del siglo XIX, Sofía Mastrangelo (trad.), Fondo de Cultura Económica, México.

\section{Archivos}

Cineteca Nacional Expedientes Hemerográficos 